\title{
A rapid and simple fluorimetric determination of iodide in iodized table salts
}

\author{
V. A. Kabasakalis* and M. G. Mitrakas \\ Lab. of Analytical Chemistry, Chemical Engineering Department, Faculty of Engineering, \\ Aristotle University of Thessaloniki, Thessaloniki 54006, Greece
}

\begin{abstract}
A new, simple and rapid fluorimetric method is proposed for the determination of iodide in iodized table salts based on the fluorescence exhibited by the ionic complex formed between $\mathrm{AgI}_{2}{ }^{-}$and the brilliant green cation $\left(\ddot{\mathrm{e}}_{\mathrm{exc}}=256 \mathrm{~nm}\right.$, $\left.\ddot{e}_{\mathrm{em}}=521 \mathrm{~nm}\right)$ at $\mathrm{pH} 3.0$ and $\mathrm{Ag}^{+}$concentration of $0.8 \mathrm{mg} / \mathrm{L}$. The relationship between fluorescent response expressed as Fluorescence Intensity Units (FIU) and KI concentration of standards in $20 \mathrm{~g} \mathrm{NaCl} / \mathrm{L}$ was linear in the range of 0.15 to $1.2 \mathrm{mg} \mathrm{KI} / \mathrm{L}$. The sensitivity of the method was $300 \mathrm{FIU}$ for $1 \mathrm{mg} \mathrm{KI} / \mathrm{L}$ with a detection limit of $0.15 \mathrm{mg} \mathrm{KI} / \mathrm{L}$. The proposed method was applied in commercial iodized table salts and the results obtained were correlated closely to those obtained by the official method of the AOAC.
\end{abstract}

Key words. Iodide determination - table salt - fluorimetry.

\section{Introduction}

Iodine is an essential trace element in human nutricion with the normal dietary requirements reaching up to approximately $75 \mathrm{mg}$ iodine per year. In most countries this supply is secured by State regulations which demand the addition of KI to table salt intended for human consumption. Therefore, table salt industries are very much concerned about monitoring KI content in their products with an analytical method which should be rapid, inexpensive and sensitive. Several methods have been published for the quantification of iodide in table salts. The acceptable method by the Official Methods of Analysis of the AOAC [1] is time consuming, taking more than 2 hours for obtaining the results and so do the catalytic [2] and photometric [3] titration methods. Flow injection analysis [4] which involves photometric detection based on the catalytic fading effect of either iodate or iodide on the indicator reaction of iron(III) thiocyanate and nitrite, improves the detection limit and minimizes considerably the time consumed, but it is limited up to $2 \% \mathrm{NaCl}$ solution. A very low detection limit is also achievable by Negative Thermal Ionization Mass Spectroscopy [5] and atmospheric pressure helium Microwave Induced Plasma Atomic Emission Spectroscopy which is an indirect method and uses continuous-flow coldvapor generation of mercury [6]. Both methods, however, employ particularly expensive equipment. Iodide in table salt has also been analyzed by High Performance Liquid Chromatography [7] with a detection limit of $20 \mathrm{mg}$ iodide/ $\mathrm{kg}$ salt which is not acceptable by the table salt industries.
The objective of this study was to develop and propose a new simple, rapid and inexpensive fluorimetric method for the determination of iodide in iodized table salts and concentrated $\mathrm{NaCl}$ solutions. The method, based on the fluorescent radiation emitted from the ion-associated complex, formed between $\mathrm{AgI}_{2}^{-}$and the brilliant green cation, should possess low detection limit and increased sensitivity, attributes which meet the requirements of the table salt industries.

\section{Experimental}

\section{Reagents}

A. Stock, standard KI solution: $1000 \mathrm{mg} / \mathrm{L}$ analytical grade $\mathrm{KI}$, in distilled water.

B. Working standards: $0,0.2,0.4,0.6,0.8,1.0$ and $1.2 \mathrm{mg} \mathrm{KI} / \mathrm{L}$ in $20 \mathrm{~g} / \mathrm{L}$ of $\mathrm{NaCl}$, made by proper dilution of the stock standard solution.

C. A $40 \mathrm{mg} \mathrm{Ag}^{+} / \mathrm{L}$ solution, prepared by proper solution of a BDH standard solution of $1000 \mathrm{mg} \mathrm{Ag}^{+} / \mathrm{L}$.

D. Brilliant green solution, made by dissolving $0.75 \mathrm{~g}$ reagent (BDH no C.I 42040) in $1 \mathrm{~L}$ of distilled water.

E. $0.1 \mathrm{~N} \mathrm{H}_{2} \mathrm{SO}_{4}$ solution

F. Alternative working standards: i) $0,0.08,0.2,0.4,0.6$, $0.8,1.0$ and $1.2 \mathrm{mg} \mathrm{KI} / \mathrm{L}$ in 10 and $50 \mathrm{~g} / \mathrm{L} \mathrm{NaCl}$ and ii) $0,2.0,5.0,15,20,25,30,35 \mathrm{mg} \mathrm{KI} / \mathrm{L}$ in different concentrations of $\mathrm{NaCl}$, namely, 100,150 and $200 \mathrm{~g} / \mathrm{L}$ made by proper dilution of the stock standard solution. The above mentioned $\mathrm{NaCl}$ concentrations were achieved by dissolving the proper quantities of analytical grade $\mathrm{NaCl}$ in distilled water. 
Table I. Linear range of the calibration graphs and detection limit of $\mathrm{KI}$ in different $\mathrm{NaCl}$ concentration. The results are also expressed as $\mathrm{mg} \mathrm{KI} / \mathrm{kg}$ salt.

\begin{tabular}{lcccc}
\hline $\mathrm{NaCl}, \mathrm{g} / \mathrm{L}$ & $\mathrm{KI}, \mathrm{mg} / \mathrm{L}$ & Linear Range & \multicolumn{2}{c}{ Detection Limit } \\
$\mathrm{mg}$ KI / kg salt
\end{tabular}

\section{Recommended procedure}

A $10 \mathrm{~g}$ table salt sample is dissolved in $500 \mathrm{~mL}$ of distilled water and the solution is filtered through a $0.45 \mu \mathrm{m}$ filter. To $50 \mathrm{~mL}$ of the sample solution as well as of the working standards (B), $1 \mathrm{~mL}$ of reagent $\mathrm{C}$ is added with continuous stirring, the $\mathrm{pH}$ is adjusted to 3.0 by small additions $(0.1-$ $0.3 \mathrm{~mL}$ ) of reagent $\mathrm{E}$ and then $1 \mathrm{~mL}$ of reagent $\mathrm{D}$ is added. Fluorescence intensity measurements at $521 \mathrm{~nm}\left(\ddot{e}_{\mathrm{em}}\right)$ after excitation at $256 \mathrm{~nm}\left(\ddot{e}_{\text {exc }}\right)$, of samples and standards are taken within 5 to 10 min after reagent $\mathrm{D}$ addition. The calibration graph of Fluorescence Intensity Units (FIU) versus $\mathrm{KI}$ concentration in solution is constructed and KI concentration of the unknown sample is read from the graph.

\section{Checking the analytical conditions}

The influence of high $\mathrm{NaCl}$ concentrations on complex formation and its fluorescent response was also tested by obtaining calibration graphs using the alternative working standards (F) and the procedure described above.

\section{Materials tested}

The recommended procedure was applied to five table salt samples (no 1-5, Tab. II) which were provided by the Greek salt industry AEGEAN S.A. These samples were intended to be distributed in Serbia and their KI concentration was expected to range between $15-30 \mathrm{mg} / \mathrm{kg}$ salt. Another five samples (no 6-10, Tab. II) were obtained from the Greek market and their KI concentration, according to the Greek Legislation, should range between $40-60 \mathrm{mg} / \mathrm{kg}$ salt.

\section{Official method}

Iodide analysis of the unknown samples was also performed by the Official Method AOAC (1990) and served as a standard for comparisons.

\section{Results and discussion}

Determination of KI content was based on measurements of the fluorescent radiation emitted from the ion-association complex, formed between $\mathrm{AgI}_{2}^{-}$and the brilliant green cation and relate it to KI concentration in solution. In a pre-
Table II. Iodide analysis of table salts by the recommended fluorimetric method. The results are compared to those obtained using the Official method (AOAC, 1990).

\begin{tabular}{|c|c|c|c|}
\hline \multirow[b]{2}{*}{ Sample no } & \multicolumn{2}{|c|}{ Fluorimetric method $(x)$} & \multirow{2}{*}{$\begin{array}{l}\text { Official method (y) } \\
\text { mg KI / kg salt }\end{array}$} \\
\hline & mg KI / kg salt & $\mathrm{CV}$ & \\
\hline 1 & 18.2 & 2.8 & 17.4 \\
\hline 2 & 19.1 & 2.5 & 18.1 \\
\hline 3 & 25.1 & 3.1 & 24.6 \\
\hline 4 & 28.9 & 2.6 & 28.2 \\
\hline 5 & 28.5 & 2.2 & 28.3 \\
\hline 6 & 30.8 & 4.2 & 32.7 \\
\hline 7 & 58.6 & 1.4 & 58.9 \\
\hline 8 & 34.9 & 1.9 & 35.8 \\
\hline 9 & 45.9 & 1.6 & 44.5 \\
\hline \multirow[t]{2}{*}{10} & 29.9 & 3.8 & 30.2 \\
\hline & $\begin{array}{c}\text { Correlation coefficient } \\
\qquad r^{2}=0.9969\end{array}$ & & $\begin{array}{l}\text { Regression equation } \\
y=1.0138 x-0.56\end{array}$ \\
\hline
\end{tabular}

vious work [8] the optimum conditions for complex formation have been established, namely $\mathrm{pH}=3.0$, concentration of brilliant green $15 \mathrm{mg} / \mathrm{L}$ and measurement time within 10 min after complex formation. In this work the concentration of $\mathrm{Ag}^{+}$that would give the optimum fluorescent response was investigated. The experimental results showed that the fluorescent response, expressed as Fluorimetric Intensity Units (FIU), of a standard containing $0.5 \mathrm{mg} \mathrm{KI} / \mathrm{L}$ in $20 \mathrm{~g} \mathrm{NaCl} / \mathrm{L}$ was increased as the concentration of $\mathrm{Ag}^{+}$ increased up to $2 \mathrm{mg} / \mathrm{L}$ (Fig. 1). As it is seen from figure 1, fluorescent response (sensitivity) of $0.5 \mathrm{mg} \mathrm{KI} / \mathrm{L}$ in $20 \mathrm{~g} / \mathrm{L}$, is approximately 200 FIU and would certainly increase for $1 \mathrm{mg} \mathrm{KI} / \mathrm{L}$ (see follow discussion) at values that are considered satisfactory, since they could detect differences in concentration of $1 \mathrm{mg} \mathrm{KI} / \mathrm{kg}$ salt. A $0.8 \mathrm{mg} / \mathrm{L}$ concentration of $\mathrm{Ag}^{+}$was chosen for convenience reasons and reagent saving. Higher $\mathrm{Ag}^{+}$concentrations could be used, however, in cases where increased sensitivity and a lower detection limit, is needed. 


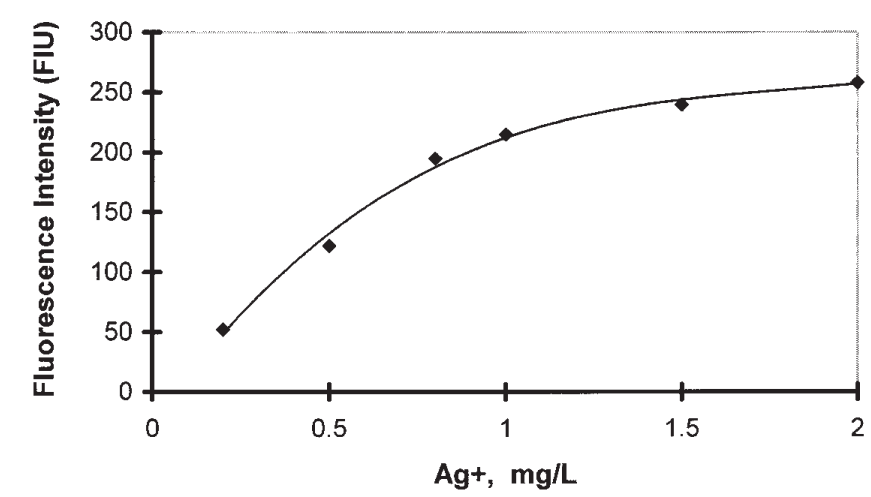

Figure 1. Effect of $\mathrm{Ag}^{+}$concentration on the fluorescence intensity of $0.5 \mathrm{mg} / \mathrm{L} \mathrm{KI}$ in $20 \mathrm{~g} / \mathrm{L} \mathrm{NaCl}$ solution.

The calibration graphs relating fluorescent response (FIU) and $\mathrm{KI}$ concentration in 10, 20, 50, 100, 150 and $200 \mathrm{~g} / \mathrm{L} \mathrm{NaCl}$ solutions were obtained for studying the behavior of the complex formation and its subsequent fluorescence in the presence of varying concentrations of $\mathrm{NaCl}$. The experimental results showed that the graph was linear between 0 to $1.4 \mathrm{mg} \mathrm{KI} / \mathrm{L}$ and that $\mathrm{NaCl}$ concentrations from $10 \mathrm{~g} / \mathrm{L}$ to $50 \mathrm{~g} / \mathrm{L}$ did not affect the slope of the calibration graphs, which was almost constant at $290 \pm 10$ FIU (Fig. 2). However, as $\mathrm{NaCl}$ concentration was increased, the linear range of the calibration graph was displaced towards higher KI concentration (Fig. 2). The detection limit, defined as 3 of 7 replicates of blank solution [9] was also increased from $0.07 \mathrm{mg} \mathrm{KI} / \mathrm{L}$ in $10 \mathrm{~g} / \mathrm{L} \mathrm{NaCl}$ solution to $0.32 \mathrm{mg} / \mathrm{L} \mathrm{KI}$ in $50 \mathrm{~g} \mathrm{NaCl} / \mathrm{L}$ (Tab. I). At higher $\mathrm{NaCl}$ concentrations, apart from the displacement of the linear range towards higher KI concentration and the increase of the detection limit from $1.9 \mathrm{mg} \mathrm{KI} / \mathrm{L}$ in $100 \mathrm{~g} \mathrm{NaCl} / \mathrm{L}$ to $9.5 \mathrm{mg} \mathrm{KI} / \mathrm{L}$ in $200 \mathrm{~g}$ $\mathrm{NaCl} / \mathrm{L}$ (Tab. I), a decrease of sensitivity (slope of the calibration graph) was noticeable as well. So, the slope decreased from 300.08 in $50 \mathrm{~g} \mathrm{NaCl} / \mathrm{L}$ to 91.5 in $100 \mathrm{~g}$ $\mathrm{NaCl} / \mathrm{L}$ and 15.4 in $200 \mathrm{~g} \mathrm{NaCl} / \mathrm{L}$ (Fig. 3).

On the basis of the data of table I and figure 2, calibration standards in $20 \mathrm{~g} \mathrm{NaCl} / \mathrm{L}$ and dissolution of $20 \mathrm{~g}$ of the unknown sample in $1 \mathrm{~L}$ of water were chosen, for the determination of KI content of table salts. These analytical parameters cover the expected KI concentration in table salts, which ranges between 15 to $60 \mathrm{mg} \mathrm{KI} / \mathrm{kg}$ salt in accordance to the State Legislation of the European countries. The proposed method was tested by analyzing samples no 1-5 (Tab. II) whose concentration varied between 15-30 mg $\mathrm{KI} / \mathrm{kg}$ salt, and samples no 6-10 obtained from the Greek market.

Iodide content of all samples was also determined by the Official Method of Analysis of the AOAC (1990) as well. KI concentration values obtained by the proposed fluori-

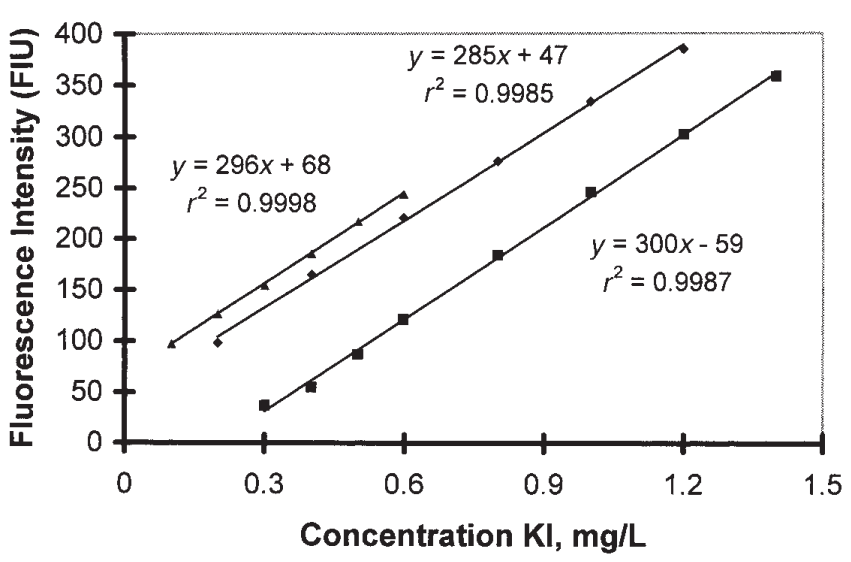

Figure 2. KI calibration graphs in various $\mathrm{NaCl}$ solutions: ${ }_{10}$ $\mathrm{g} / \mathrm{L}, \quad 20 \mathrm{~g} / \mathrm{L}, \quad 50 \mathrm{~g} / \mathrm{L}$.

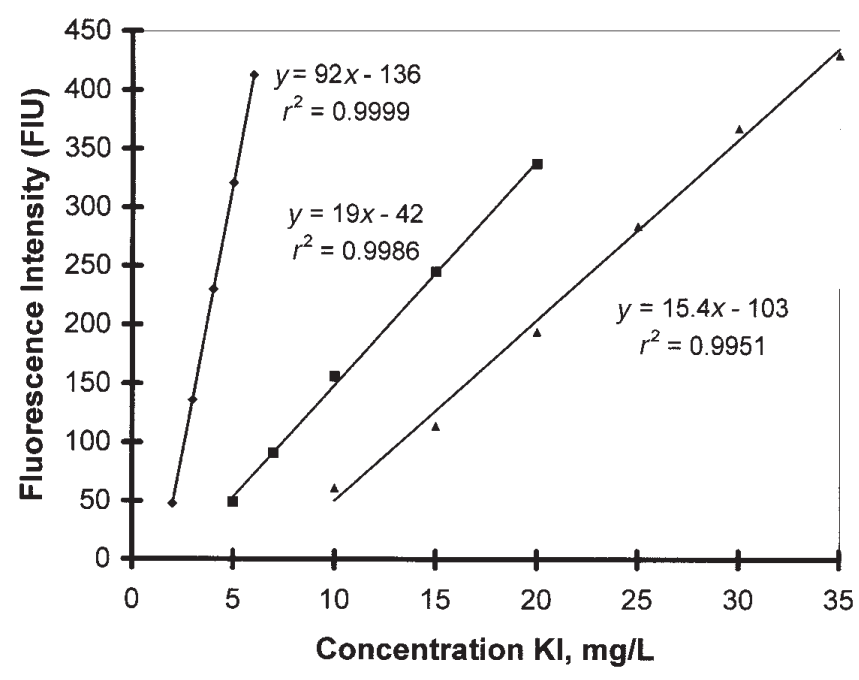

Figure 3. KI calibration graphs in $\mathrm{NaCl}$ solutions of high concentration: $100 \mathrm{~g} / \mathrm{L}, \quad 150 \mathrm{~g} / \mathrm{L}, \boldsymbol{\Delta} 200 \mathrm{~g} / \mathrm{L}$.

metric method were correlated closely to those obtained by the official method (Tab. II). The regression line had a slope and an intercept not statistically different from 1 and 0 respectively, at $1 \%$ level of probability. The method was also proved precise since the coefficient of variation $(\mathrm{CV})$, estimated from 7 replicates, was less than $5 \%$ on the average (Tab. II). It is remarked that KI concentration of the AEGEAN industry samples, destined for Serbia, was within the limits imposed by Serbian Legislation. On the contrary, in 3 samples sold in the Greek market KI concentration was lower than the one written on the container. 


\section{Letter}

In conclusion, the proposed fluorimetric method for iodide determination in iodized table salts gave reproducible results and similar to those obtained by the official method of analysis. An additional advantage of the fluorometric method stems from its simplicity and rapidity requiring less than 10 minutes time of analysis.

\section{Acknowledgements}

Authors thank the salt industry "AEGEAN S.A." for its support.

\section{References}

1. Official Methods of Analysis of the A.O.A.C. Helrich, K. Ed., Method 925.56, 1990, Vol. 1, pp 335.
2. Timotheou-Potamia, M.; Hadjiioannou, T. Mikrochimica Acta 1983, 11, 59-63.

3. Pesavento, M.; Biesuz, R. Anal. Chim. Acta 1984, 158, 143146.

4. Oguma, K.; Kitada, K.; Kuroda, R. Mikrochimica Acta 1993, 110, 71-77.

5. Heumann, K.; Schindlmeier, W. Fresenius Z. Anal. Chem. 1982, 312, 595-599.

6. Nakahara, T.; Wasa, T. Microchemical J. 1990, 41, 148-155.

7. Chadha, R.; Lawrence, J. J. Chrom. 1990, 518, 268-272.

8. Kabasakalis, V. Anal. Lett. 1994, 27, 2789-2796.

9. Keith, L.; Crummett, W.; Deegan, J.; Libby, R.; Taylor, J.; Wentler, G. Anal. Chem. 1983, 55, 2210. 